\title{
TECHNICAL ASSISTANCE FOR THE CONSERVATION OF BUILT HERITAGE AT BAGAN, MYANMAR
}

\author{
D. Mezzino ${ }^{\mathrm{a}}$, M. Santana Quintero ${ }^{\mathrm{a}}$, P. Ma Pwint ${ }^{\mathrm{b}}$, W. Tin Htut Latt ${ }^{\mathrm{b}}$, C. Rellensmann ${ }^{\mathrm{c}}$ \\ ${ }^{a}$ Carleton Immersive Media Studio (CIMS), 1125 Colonel by drive, Ottawa, On, K1S 5B6 Canada, davide.mezzino@gmail.com - \\ mario.santana@carleton.ca \\ ${ }^{\mathrm{b}}$ Department of Architecture, Yangon Technological University, Gyogone, Insein Road, Yangon, p.mapwint@gmail.com - \\ wint2009@gmail.com \\ c Cultural Unit UNESCO Bangkok, c.rellensmann@unesco.org
}

Commission VI, WG VI/4

KEY WORDS: Built Heritage, Digital Documentation, Capacity Building, Photogrammetry, Electronic Distance Measurements (EDM), Laser Scanning, Bagan.

\begin{abstract}
:
Presenting the outcomes of a capacity building activity, this contribution illustrates a replicable recording methodology to obtain timely, relevant and accurate information about conditions, materials and transformations of heritage structures. The purpose of the presented training activity consisted in developing local capabilities for the documentation of the built heritage at Bagan, Myanmar, employing different IT-supported techniques. Under the Director of UNESCO, the direct supervision of the chief of the culture unit, and in close consultation and cooperation with the Association of Myanmar Architects, the Department of Archaeology National Museum and Library (DoA) a documentation strategy has been developed in order to set up a recording methodology for the over three thousand Bagan monuments. The site, located in central Myanmar, in South East Asia, was developed between the IX and the XIII century as capital of the Myanmar kingdom. In the last years, this outstanding site has been exposed to an increasing number of natural hazards including earthquakes and flooding that strongly affected its built structures. Therefore, a documentation strategy to quickly capture shape, color, geometry and conditions of the monuments, in order to develop proper conservation projects, was needed. The scope of the training activity consisted in setting up a recording strategy updating the existing Bagan inventory, using three Buddhist temples as pilot cases study. The three documented temples were different in size, construction period, conditions and shape. The documentation included several IT-supported techniques including: Electronic Distance Measurements (EDM), SFM Photogrammetry, Laser Scanning, Record Photography as well as hand measurement and field notes. The monuments' surveying has been developed in accordance with the guidelines and standards established by the ICOMOS International Committee for Documentation of Cultural Heritage (CIPA). Recommendations on how to extend the adopted methodology to the other Bagan monuments have been also elaborated.
\end{abstract}

\section{INTRODUCTION}

\subsection{Scope of work and training}

The main scope of the work consisted in a capacity building activity to develop local capabilities in the documentation of Bagan built heritage, employing different IT-supported techniques. The mission of the project consisted in setting up a recording strategy to be extended to all Bagan monuments. Therefore, during the field project a systematic documentation strategy employing different recording techniques and tools to capture shape, colour, spatial configuration and current conditions of three selected monuments has been developed. The training activity was addressed to the local department of archaeology and to emerging heritage professionals, professor from the Yangon Technological University and local experts. The workshop lasted twelve days. It has been structured in nine days of field work and three days of data processing. The goals of the work included:

- the understanding of the role of visual information gathering in recording archaeological sites;

- the acquisition of skills on how to use recording techniques to quickly capture the current conditions of Bagan built heritage;
- learning how to integrate information gathered through these techniques into coherent presentations;

- working in teams throughout the workshop, ultimately completing a graphic record of Phya-sa-shwe-gu, Nan-hpaya and Ananda temples;

- undertake capacity building in the surveying of monuments in accordance with the guidelines and standards established by the ICOMOS International Committee on Heritage Documentation (CIPA);

- developing a surveying strategy for other monuments in the Bagan's site, to update the existing inventory, in vision to the World Heritage nomination;

- set up a methodology of inventory of Bagan monuments considering the constant natural hazards (in particular seismic threat ${ }^{1}$ ).

The project has been supported and developed by four main stakeholders including: the United Nations Educational,

\footnotetext{
${ }^{1}$ In the event of an earthquake the inventory would provide archival assistance for any restoration, being able to preserve the memory of the monuments in case of destruction. Indeed, the area has been strongly affected by a devastating earthquake in 1975 with a magnitude of 6.5 and more recently in 2012 with a magnitude of 6.8. Currently, the region still has a high degree of potential seismicity. Further, the site is constantly affected by flooding due to the constant and heavy rains in the monsoon season
} 
Scientific and Cultural Organization (UNESCO) funded by the Japan Fund in Trust, the Association of Myanmar Architects, the Department of Archaeology, National Museum and Library (DoA), the Yangon Technological University and the Carleton Immersive Media Studio (CIMS).

\subsection{The site of Bagan}

The site of Bagan is located in the centre of Myanmar in the south east Asia. It is one of the most interesting and ancient Asian heritage sites with over three thousand monuments scattered over an area of almost seventy square kilometres.

The area of Bagan (or "Pagan" as it is also called) includes three main areas: the lively town of Nyaung $U$, the historic walled city of Old Bagan and further on the south the New Bagan (Bagan Myothit).

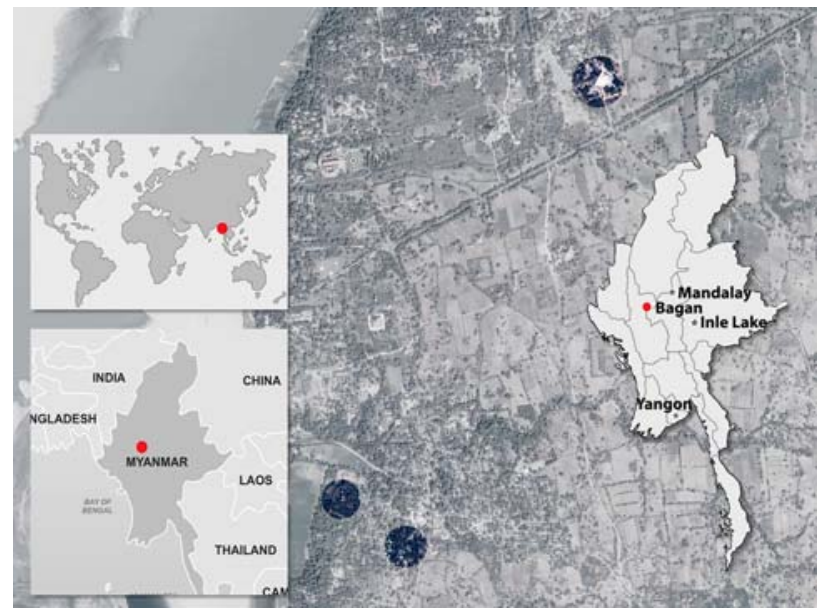

Figure 1 Territorial framework of the site of Bagan. In the image are outlined the three recorded temples.

Among these areas the site has been articulated in three main zones for a more efficient classification to support the site conservation initiatives. These include: the Monument Zone (MZ), the Ancient Zone (AZ) and the Protection Zone (PZ). From the natural point of view the area is featured by the Ayeyawadi river that crosses all Myanmar flowing into the Andaman Sea. The river is and has always been Myanmar's vital artery. Further, the raw materials of Bagan buildings' constructive elements such as bricks and mortar are strictly connected to the river.

\subsection{Bagan built heritage}

The archeologic site of Bagan was the capital of the first Myanmar kingdom from 1044 to 1287 A.D. ${ }^{2}$ The site counts more than three thousand monuments even if documentary sources report that in the past the site counted almost five thousand monuments.

In the site there are two main architectural typologies ${ }^{3}$ : the stupa and the temple ${ }^{4}$. The main difference between the two concern the accessibility and use of the building. Indeed, the stupa is a monumental structure to commemorate the Buddha or his memorable deeds. Stupas may have many different contours

\footnotetext{
${ }^{2}$ Pichard, P., Inventory of monuments at Pagan. UNESCO, Paris,1992.

${ }^{3}$ Bagan built heritage includes: monasteries, underground structures, a royal palace (mostly ruined) local housing, stupas and temples.

${ }^{4}$ Bagan temples presents different typologies: central-shrine temples, temples with a solid core, with a central shrine and corridor, twostorey, three-storey and four-storey temples.
}

but a bell-shape is most common for the larger stupas. Temples instead are a places of worship, devotion and meditation totally accessible to the public ${ }^{5}$. Generally, these buildings house Buddha images or contain sacred relics.

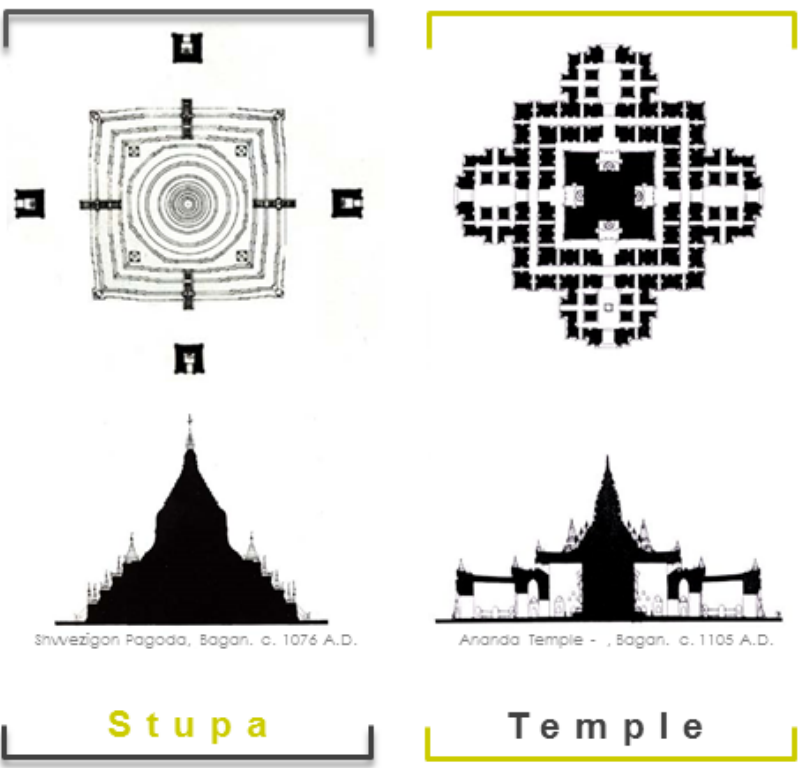

Figure 2 Representative image depicting the main difference, in term of accessibility, design and spatial distribution between stupas and temples

\subsection{Pierre Pichard inventory}

Pierre Pichard inventory developed between the 1982 and the 1991 in the framework of an United Nations Development Programme (UNDP) project was published in eight volumes between 1992 and 1995. The information provided by the inventory for each monument contains ${ }^{6}$ :

- inventory number;

- $\quad$ name of the monument;

- broad location referenced to a prominent monument, landmark or village (indeed in Bagan there are not streets names or street numbers that can be used as reference);

- coordinates;

- short description.

The short description of each monument is then articulated into ten main points. They include:

1. a general description indicating the type of monument (stupa, temple, monastery, etc.), number of storeys and size;

2. measured floor plan in scale 1:100, 1:200, 1:400, 1:500 or 1:1000 depending on the monument size. In some cases elevation(s) and a cross section(s) are also provided;

3. upper parts, providing indications about roofs, terraces, towers, shrines, domes, spires, stupas, etc.

4. construction information including materials and construction techniques;

5. present conditions and date of eventual previous interventions (when known);

\footnotetext{
${ }^{5}$ Even if in the past their accessibility was ruled by a complex hierarchy distinguish between monks and common people, currently they are accessible by everyone.

${ }^{6}$ This section extensively refer to: Pichard, P., Inventory of monuments at Pagan. UNESCO, Paris, 1992.
} 
6. images illustrating the monument conditions as well as the character defining elements such as: contextual views, details and decorative apparatus;

7. $\quad$ information about the decorative apparatus including elements such as: stucco mouldings, mural paintings, glazed terracotta tiles, etc. This section indicates also the estimated percentage of the original decoration;

8. epigraphy, documenting eventual stone inscriptions, ink captions or graffiti.

9. references to previous works and publications;

10. estimated construction period.

The inventory analysis has been the starting point for the development of the recording strategy and to establish the goals of the training approaches.

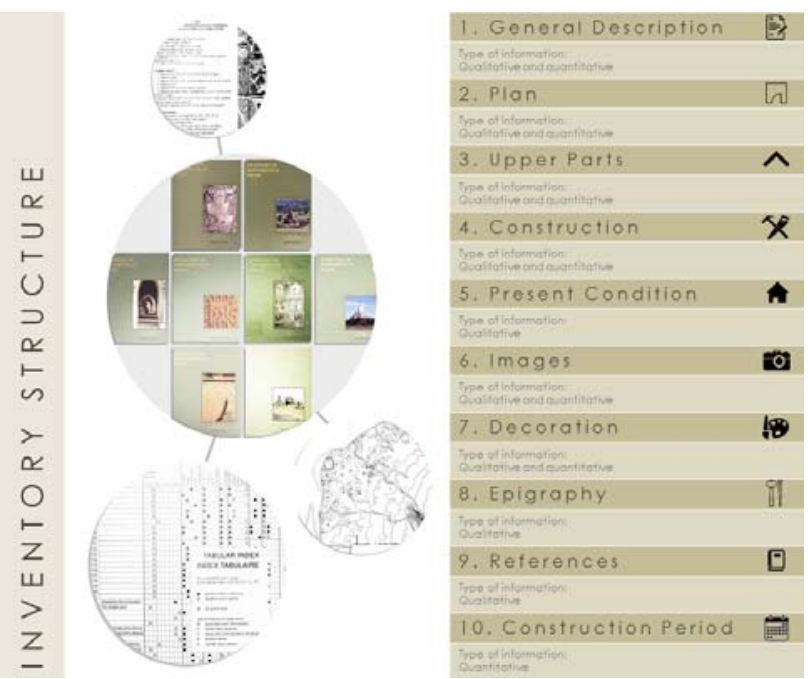

Figure 3 Diagram of the structure of the inventory developed by Pierre Pichard.

\section{TRAINING APPROACH}

\subsection{Training strategy}

For the training workshop three temples have been selected. These buildings still used as worship, devotion and meditation places are different in terms of: construction period, size, conditions and decorative apparatus.

The choice of heterogeneous monuments, representative of the architectural diversity and creativity of Bagan built heritage, was aimed at developing a flexible recording strategy that could be extended to the whole site.

The training activity developed a documentation strategy considering:

- the historical framework of each temple in relation with its site development;

- a territorial framework, including a study of the natural elements and infrastructures (both historical and modern ones).

The training approach involved three main phases.

The first phase involved the survey of three temples employing different techniques, including Electronic Distance Meter (EDM), Digital Photogrammetry, Laser Scanning and Recording Photography. In order to save time and speed up the recording the working group was split into two different teams. One team dealt mainly with Electronic Distance Meter techniques while the other one with Photogrammetry and Laser Scanning.
The second phase consisted in processing the raw data obtained from the first phase. The resulting outputs laid the groundwork for developing the condition assessment of the temples.

At the final stage, recommendations for further surveys and eventual conservation projects were provided based on the results of the previous analysis.

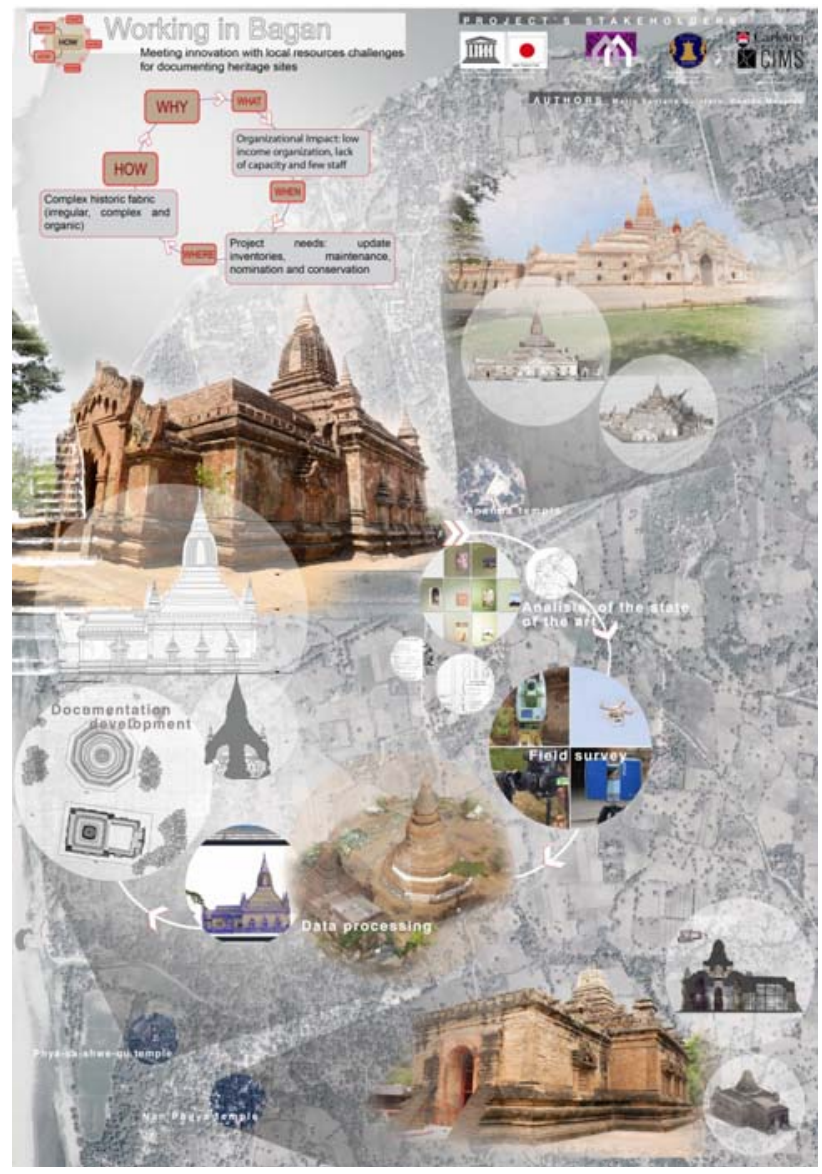

Figure 4 Image illustrating the three recorded temples in the site of Bagan.

\subsection{Documentation component}

The documentation components to be elaborated for the conservation of the recorded structures included:

- a preliminary visual condition report;

- field notes and sketches;

- measured drawings (site plans, floor plans, cross sections and elevations);

- a digital photographic portfolio;

- panoramic photos;

- a report describing the documentation strategy and the obtained results;

- $\quad$ guidelines and protocols.

To provide additional information and increase the detail level of the Pierre Pichard inventory the measured drawings have been elaborated in scale 1:100 and 1:50.

\section{RECORDING STRATEGY}

Considered the context of Bagan, the adopted recording strategy employed different IT supported techniques as well as hand measurements. The recording strategy has been designed considering the needs of the local stakeholders, the skills of the 
Local Department of Archaeology (DoA), time, tools and resources available.

\subsection{Survey toolbox specification}

The documentation of the three temples has been carried out employing different techniques: Electronic Distance Measurement (EDM), terrestrial and aerial Photogrammetry, Laser Scanning, Record Photography and Hand Measurements. The digital recording has been carried out with the support of several surveying instruments, among them, a Total Station equipped with Electronic Distance Measurement (EDM), DSLR cameras, a GPS device and a Laser Scanner. More specifically, the list of the equipment included:

- Leica Geosystems Total Station TS11, with a distance accuracy of $2 \mathrm{~mm}$ and angular $2 \mathrm{ppm}$ for linework;

- $\quad$ Nikon D800 DSLR camera with 36 MP;

- tripod;

- Drone Phantom 2 Vision +;

- fisheye Nikkor $10.5 \mathrm{~mm}$ lens;

- Faro Laser Scanner Focus3D.
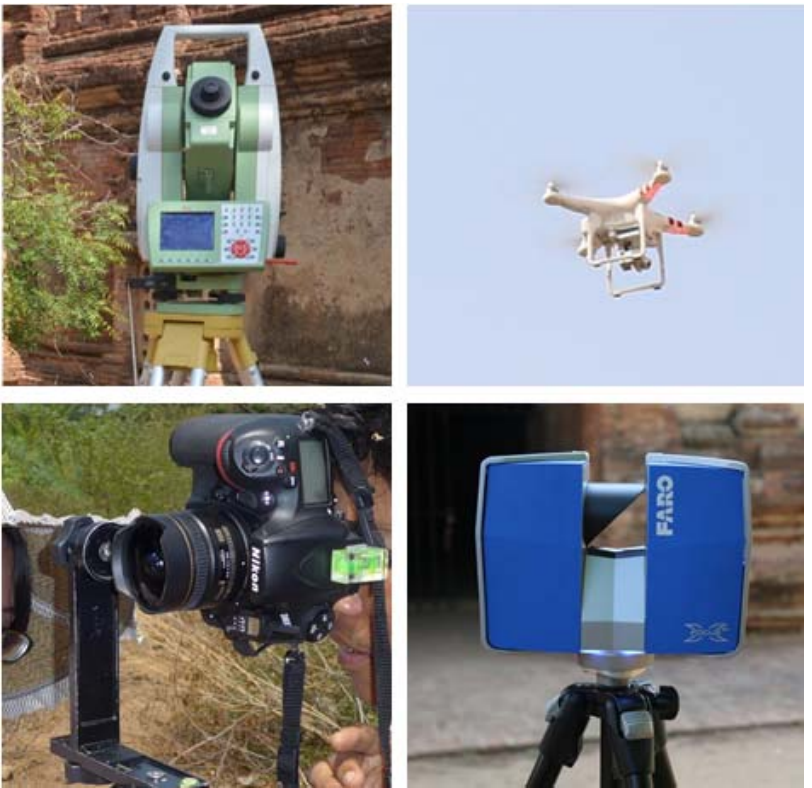

Figure 5 List of the employed equipment.

\subsection{Field notes and Sketches}

Sketches and field notes have been used primarily during the field survey phase to produce reference key plans for the location and point identification of the EDM targets and station points of both: Total Station and of the Laser Scanner. This information has been useful also during the data processing phase.

\subsection{Hand measurements}

Hand measurements have been developed employ Running Dimension and Triangular Measurement. In this phase also an Distance measuring (DISTO) has been used. This information has been compared and integrated with the measurements coming from the Total Station as well as from the point cloud (generated with Photogrammetry and Laser Scanning techniques).

\subsection{Total station survey}

Reflectorless Electronic Distance Meter (REDM) has been employed to survey interior and exterior of the recorded temples. The first step of the Total Station survey consisted in setting up the survey network. The survey network, connecting interior and exterior of each temple has been calculated using a Leica Total Station TS11, owned by the CIMS. The network has been closed, verified and adjusted employing traversing calculations. The survey network supported the Photogrammetric and Laser Scanning records. Once set up the survey network it has been possible to draw the outline of the walls and of the main elements of the temples directly in AutoCAD from the Total Station. The lines in AutoCAD have been divided into different layers such as: windows, wall sections, projected lines, vaults and arches projections, etc. The same approach has been employed for recording the interior and exterior of the three recoded buildings. Considering the short time frame of the workshop, Reflectorless Electronic Distance Meter (REDM) has been an efficient technique to be learnt.

\subsection{Global Positioning of the survey network}

Thanks to a GPS Garmin device, owned by the local department of archaeology, the station points of the Total Station has been measured in order to locate the survey in a broader context. Eight station points of the survey networks have been used to geo-reference the Total Station measurements. The GPS measurements have been processed in ArcGIS in order to geolocate the site plan. In this phase it has been considered how the GPS device indicated an average accuracy in the ranges of 3 meters.

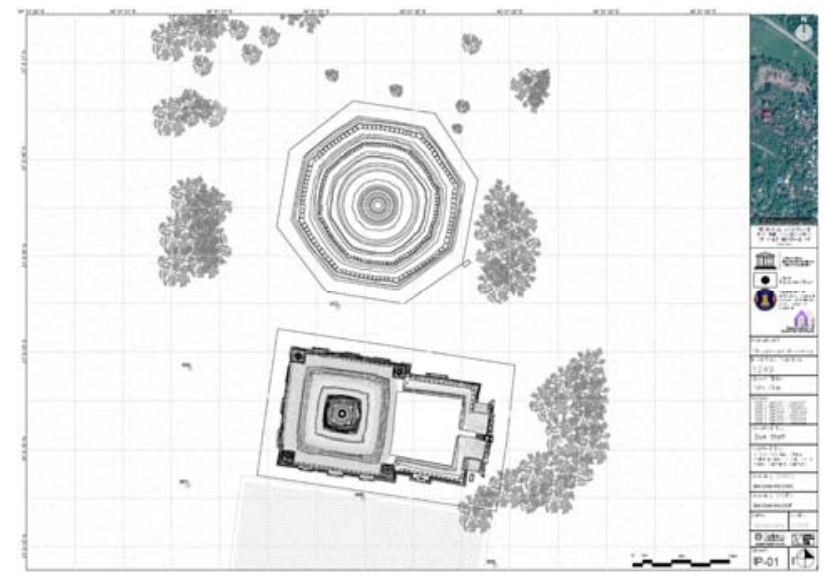

Figure 6 Geo-localized site plan of the Phya-sa-shwe-gu temple.

\subsection{Photogrammetry}

Photogrammetry has been an efficient technique to be applied in the context of Bagan. It provided spatial (from the generated point cloud) and qualitative (from the pictures) data. This technique allowed to capture elements that were difficult to survey by Total Station, such as stupas, terraced roofs, stucco works, wall paintings, brickworks, mouldings and windows.

In the data acquisition phase, photos of the elevations have been taken according to the photogrammetric rule (3x3), established by CIPA (ICOMOS CIPA, 2013), using photogrammetric strips with $60-80 \%$ of overlap. The photos were taken at an appropriate scale in order to capture the details of the structure, given that the drawing set was produced at 1:100 and 1:50 scale. The photos were referenced to the Total Station data and 
the project coordinate system, using the targets on the elevations captured in the same photos.

To capture roofs, stupas and shrines aerial photogrammetry has also been employed. An Unnamed Aerial Vehicle (UAV) Drone Phantom 2 Vision + has been deployed to capture video and images of the upper parts of the temples. Photogrammetry models were created using the PhotoScan software.

Photogrammetry has been a good recording strategy for the Bagan built heritage considering surfaces heterogeneity and the irregular shape of its monuments, also due to the high level of damages of the temples. Due to these conditions the algorithm of the photogrammetric software worked very efficiently.

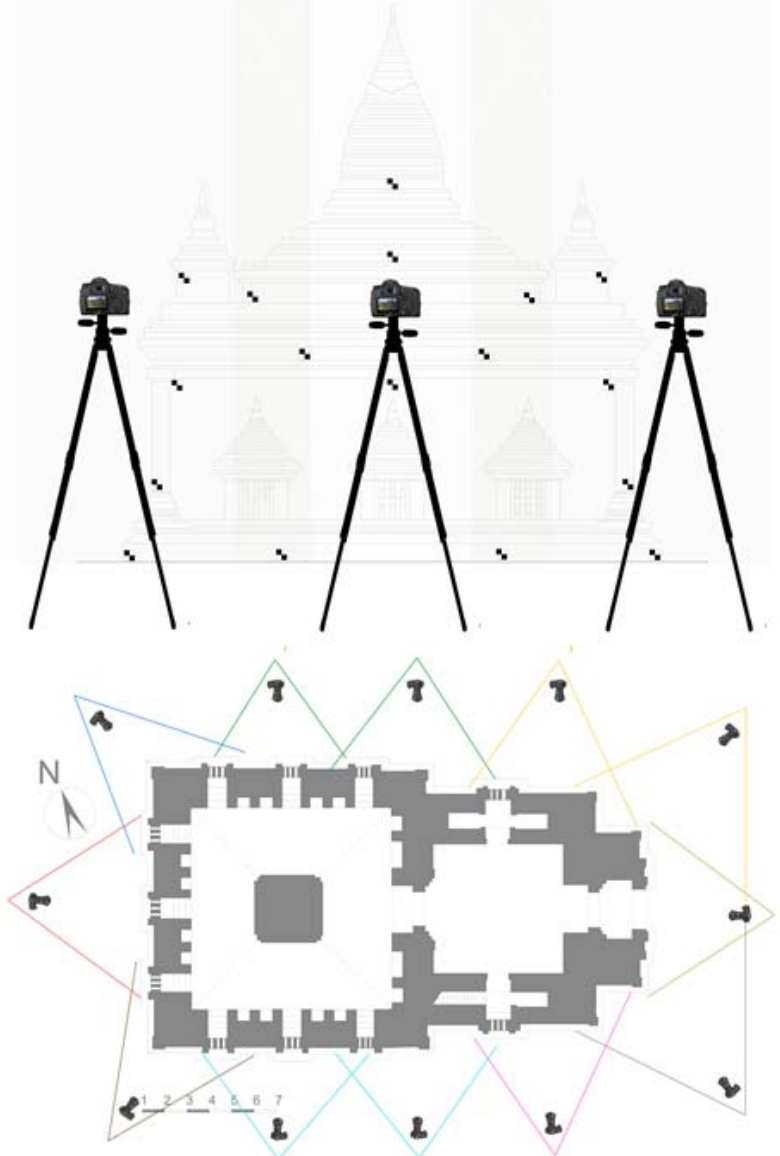

Figure 7 Images showing the method followed in capturing the photos to be processed in the photogrammetric software.

\subsection{Laser Scanner}

This technique has been particularly useful to reach an high detail level of the final outcomes in a short time. Indeed, thanks to the Faro Laser Scanner Focus3D it has been possible to capture up to 976,000 points/second with an accuracy of \pm $2 \mathrm{~mm}$. Further, this tool had also the advantage to be a portable high resolution scanner.

This technique allowed to capture the detail of the different pathologies and cracks as well as the myriad of forms, motifs and symbols of the stucco mouldings.

In the data acquisition phase each single scan has a point density $<7.8 \mathrm{~mm}$ due to the fact that the scans have been taken at a distance minor than 10 meters from the monument. This has been planned according to the range of the Laser Scanner included between $0.6-30 \mathrm{~m}^{7}$.

The scans have been processed and combined in the software SCENE, with a registration target based, employing the measurement of the Total Station to reference the generated point cloud.

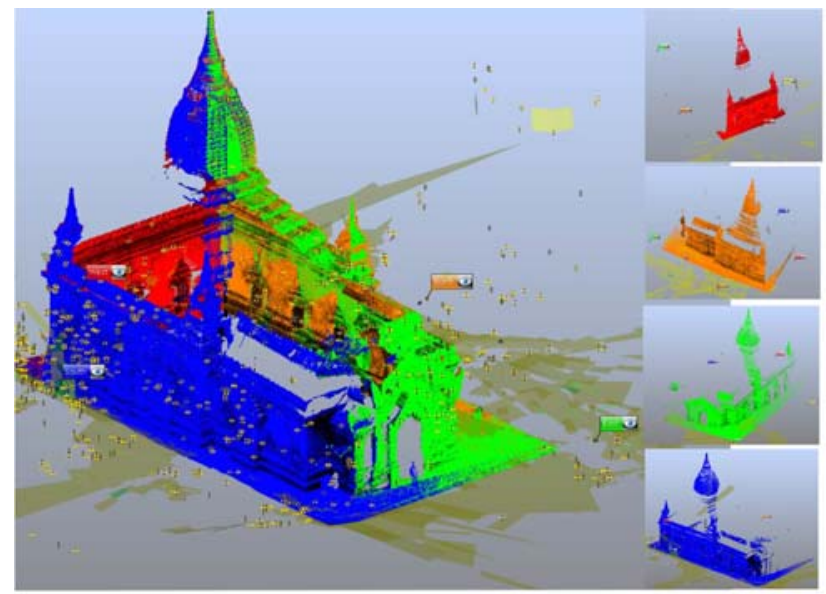

Figure 8 Image illustrating the alignment of the different scans. Software used: SCENE.

\subsection{Record photography}

During the field work, record photographs have been taken. These photographs supported the preparation of the twodimensional drawings, showing additional details of rooms surveyed. In the second phase all the photos have been referenced in a key plan indicating the exact location and orientation of the photographs.

A photographic portfolio has also been developed. It included the character defining elements of both interior and exterior as well as the condition assessment of the temples. The relevance of these photographs has been fundamental to produce an accurate analysis of the significance and condition of each temple.

\subsubsection{Panoramic Photography}

In order to have a record of the state of the art during the field survey, a set of full spherical panoramic photographs of some selected interior and exterior locations has been provided. These photographs gave an additional comprehensive visual understanding of the spatial context around and inside the temples being very useful in the data processing phase. The panoramas were prepared by stitching twelve overlapping images for a complete coverage of $360^{\circ}$ of the captured scene (eight horizontal and two bottom and top views). The images were taken using a Nikon D300 DSLR camera (12.3 megapixel DX format CMOS sensor) equipped with a fisheye Nikkor lens of $10.5 \mathrm{~mm}$ that covers a field of view of approximately $180^{\circ}$ diagonals. The taken images were then processed in PTGui Prov9.0 to merge the twelve photos in a Panoramic one.

Source: http://www.faro.com/products/3d-surveying/laser-scannerfaro-focus-3d/features Accessed on November 28, 2015. 


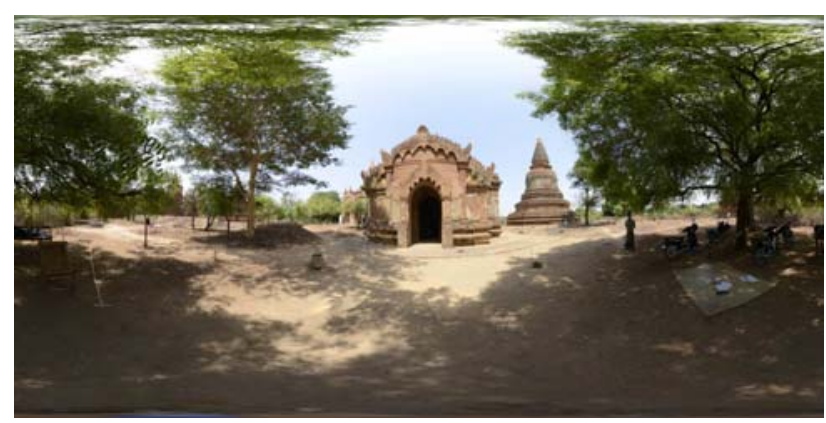

Figure 9 Example of spherical panoramic photo of the Phya-sashwe-gu temple.

\subsection{Recording buildings' exterior and interior}

The mentioned techniques have been employed for recording the exterior and interior of the three temples. During the survey phase, due to the inadequate lighting conditions inside the temples artificial lighting systems have been used.

\subsection{Two dimensional drawings production}

Once processed all the data, the point cloud data obtained through photogrammetry and laser scanning has been combined with Total Station and hand measurements in order to elaborate two dimensional drawings.

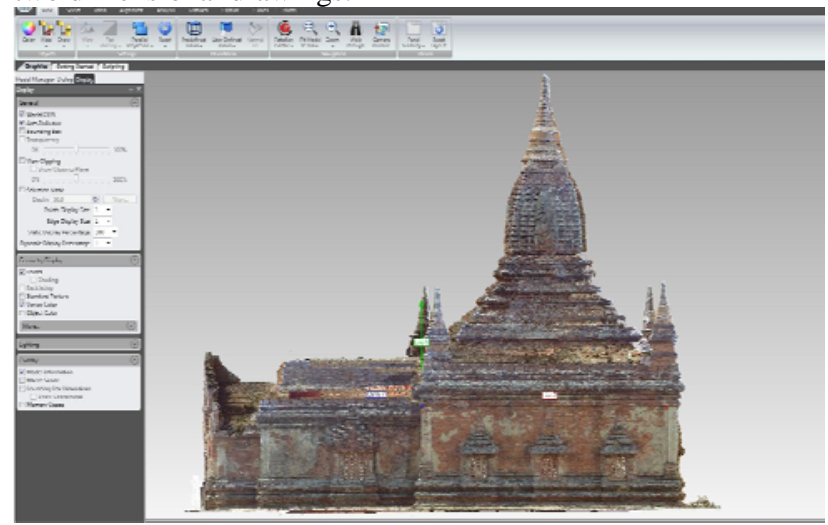

Figure 10 Point cloud model imported into Geomagic Studio 2014 to generate orthophotos.

The poinclouds coming from the different techniques have been combined in Autodesk Recap and then exported as .pts file and imported into Geomagic Studio 2014 to generate the orthophotos.

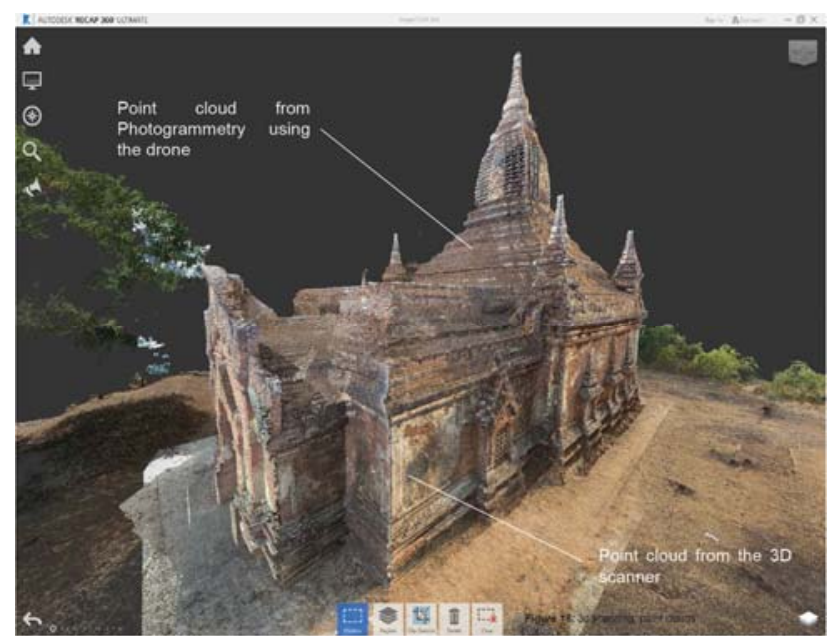

Figure 11 Combination of the point cloud of the exterior and interior of the Phya-sa-shwe-gu temple to generate a complete 3D point cloud of the building. Software employed: Autodesk Recap.

The orthophotos have then been imported in Autodesk AutoCAD where they have been traced in order to produce two dimensional line drawings.

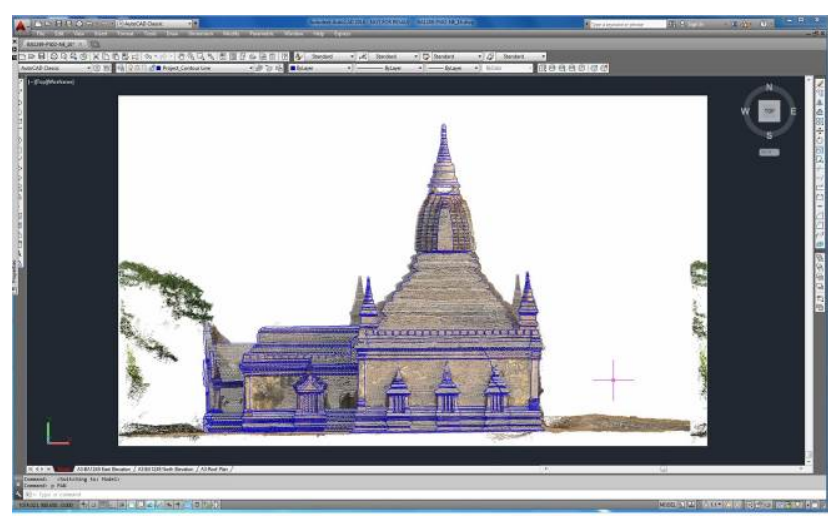

Figure 12 Orthophoto imported in AutoCAD 2014, where it has been traced to develop the $2 \mathrm{D}$ line drawings.

This approach was replicated for elevations, floorplans, cross sections, site plans and roof plans.

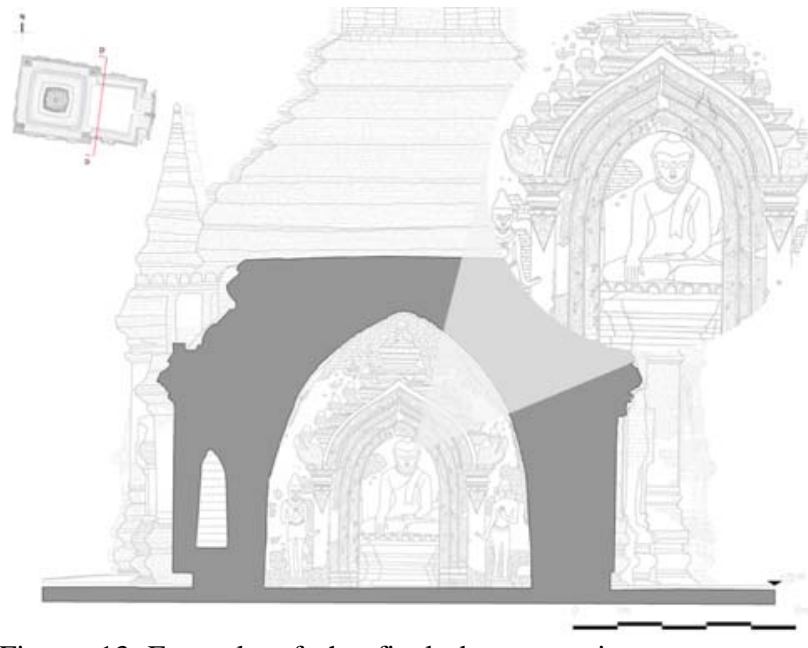

Figure 13 Example of the final documentation components elaborated in scale 1:50. 


\section{CONCLUSIONS}

The developed documentation project is the first step for an efficient conservation strategy for Bagan built heritage.

An assessment of the quality of data provided, addressing related sources of error, types of error and characteristics of data imprecision and its inaccuracies should also be developed. On a final note, possible recommendations concern the continuation of capacity building projects through desk and field work to:

- engage local team and organizations in the appropriate use of technology;

- demonstrate the benefit of reliable documentation practice;

- develop a global view as well as attention to details.

The adopted methodology should then be extended to other monuments in Bagan.

\section{FUTURE RESEARCH}

Further researches for the long term monitoring and future rehabilitation of the site include the following areas:

- documentation;

- conservation;

- engagement;

- policies.

In term of documentation, the digitalization of an updated inventory of Bagan built heritage should be developed. A technical solution could be provided by the open source application Arches, a web based and geospatial information system that could be employed for this purpose. Further, within a 3D semantic model in a BIM environment, different aspects from the structural integrity to the construction materials and techniques, building conditions (pathologies, damages, cracks) as well as character defining elements - could be documented in a spatial information model. In a BIM model it would be possible to record and manage different variables and features (tangible and intangible) of Bagan monuments for an effective and inclusive conservation for the present and future generation. Finally, a combined use of Arches application and BIM system, would be an good strategy for the monitoring of the site at the urban as well at the architectural scale.

In term of conservation, a Conservation Plan for a preventive planned preservation for the constant monitoring and maintenance of the site should be developed. Then, specifications about material compatibility, repairing techniques and preservation of the architectural integrity in the specific case of Bagan should be elaborated.

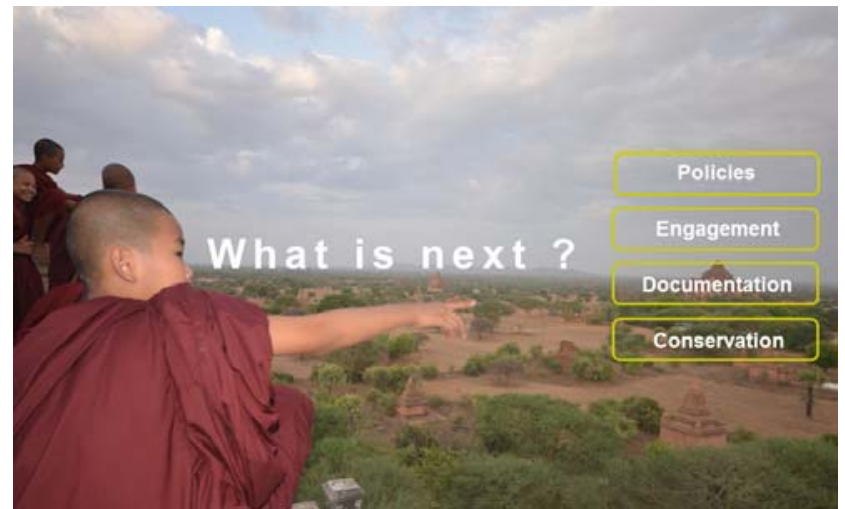

Figure 2 Image illustrating the areas of possible further research.
Increasing engagement could be reached identifying the intangible values through a bottom up approach promoting active involvement in the heritage conservation processes.

On a final note, in term of policies regional heritage charters and site-specific conservation declarations, through collaboration between planning and heritage authorities, should be developed.

\section{ACKNOWLEDGEMENTS}

The authors wish to acknowledge and thank the support of UNESCO, the Japanese Funds-in-trust, Myanmar's Department of Archaeology, National Museum and Library (DoA) and the Association of Myanmar architects for this unique opportunity to collaborate in the preservation of this important landmark. Special thanks go to our DoA trainees. In addition, we wish to thank the support of U Soe Soe Lin, Clara Rellensmann, Dr Pwint, Wint Tin Htut Latt, Saw Phyu Thein and Aung Zaw Min. As well as, the outstanding of the Carleton Immersive Media Studio (CIMS) staff. We must also acknowledge the hard work and crucial contribution of the faculty members Stephen Fai, as well as, Christian Ouimet for the support processing recording data. Also important is to point out Elizabeth Lee and Scott Lee from Cyark, they made their best to take a high-end laser scanning device to contribute to the posterity record of this important heritage site of Myanmar.

\section{REFERENCES}

Bedford, J. Papworth, H. ed. 'Measured and drawn: techniques and practice for the metric survey of historic buildings ' English Heritage, Kemble Drive, Swindon (2009), http://www.englishheritage.org.uk/content/publications/ drawn.pdf (last accessed: May 15, 2015)

Bedford,J. Pearson, T. Thomason, B. Traversing the Past, English Heritage (2011), http://www.english-heritage. org.uk/content/publications/publicationsNew/guidelinesstandards/traversingthepast/Traversing_the_Past.pdf accessed: May 15, 2015)

English Heritage '3D Laser Scanning for Heritage: Advice and guidance to users on laser scanning in archaeology and architecture', (2009), http://www.englishheritage.org.uk/publications/3d-laser-scanning-heritage2/ (last accessed: May 15, 2015)

English Heritage 'Understanding Historic Buildings: A guide to good recording practice' (2006), http://www.englishheritage.org.uk/publications/understanding-historic-buildings/ (last accessed: May 15, 2015)

English Heritage 'The Presentation of Historic Buildings survey in CAD', http://www.english-heritage.org.uk/ publications/historic-building-survey-in-cad/ (last accessed: Dec 19, 2012)

Eppich, E. Chabbi, A. ed. 'Illustrated Examples Recording, Documentation, and Information Management for the Conservation of Heritage Places' The Getty Conservation Institute, J. Paul Getty Trust (2007), http://www.getty.edu/ conservation/publications_resources/pdf_publications/ recordim.html (last accessed: May 15, 2015)

Letellier, R. Schmid, W. LeBlanc, F. 'Guiding Principles Recording, Documentation, and Information Management for 
the Conservation of Heritage Places’ The Getty Conservation Institute, J. Paul Getty Trust (2007), http://www.getty.edu/ conservation/publications_resources/pdf_publications/ recordim.html (last accessed: May 15, 2015)

Patias, P. Santana Quintero, M. Introduction to Heritage Documentation, In CIPA Heritage Documentation best practices and applications, Stylianidis, E. Patias, P. Santana Quintero, M. ed. The ICOMOS \& ISPRS Committee for Documentation of Cultural Heritage. The ISPRS International Archives of the Photogrammetry, Remote Sensing and Spatial Information Sciences, Vol. XXXVIII-5/C19. ISSN 1682-1750, http://cipa.icomos.org/fileadmin/template/doc/RELATED\%20 LITERATURE/CIPA_Series_1_2007-9.pdf (last accessed: May 15, 2015)

Pichard, P., Inventory of monuments at Pagan. UNESCO, Paris, 1992.

Santana Quintero, M., Addison, A., Severo, M. (2008). Digital Archives for Conservation and Management. In: Neuckermans H., Zambelli M., Janowiak A. (Eds.), Browsing architecture: Metadata and Beyond, Chapt. 26 (pp. 306-317). Stuttgart,

Van Genechten, B. 'Theory and practice on Terrestrial Laser Scanning: Training material based on practical applications' Santana Quintero, M. Lerma, J. ed., Universidad Politecnica de Valencia Editorial (2008), https://lirias.kuleuven.be/ handle/123456789/201130 (last accessed: May 15, 2015) 